\title{
Book review: Fractures in Knapping
}

\author{
Paul R. Preston \\ Lithoscapes Archaeological Research Foundation, Rose House, Mellguards, Southwaite, Carlisle, U.K. \\ Email:paul@lithoscapes.co.uk
}

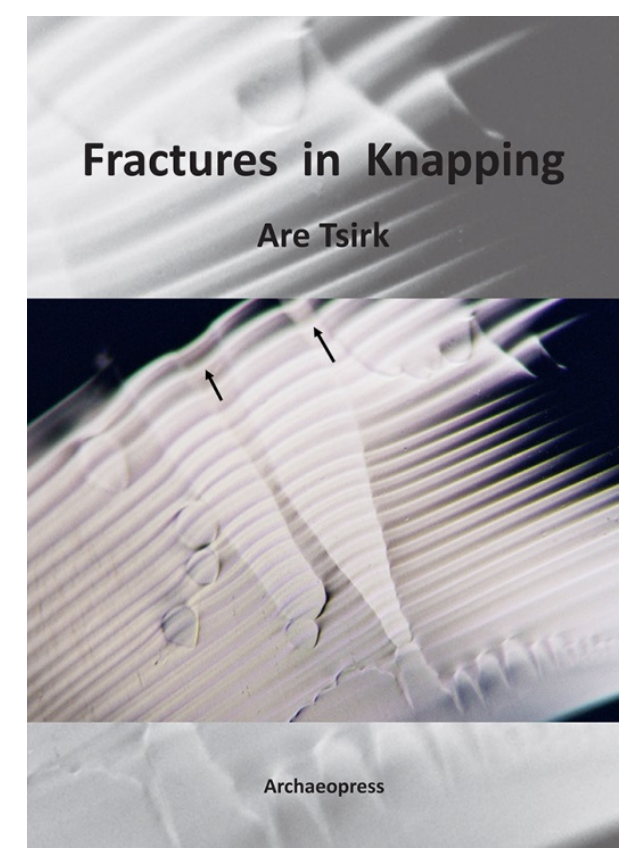

\section{Fractures in Knapping}

by Are Tsirk

Archaeopress, 2014, pp. xii+261 (includes 138 figures, 27 tables). ISBN 9781784910228

http://www.archaeopress.com/Public/displayProductDetail.asp?id=\%7B9F07CB7C-D261-45DB-

8178-D879B466343C\%7D

The book 'Fractures in Knapping' by Are Tsirk (2014) is apropos at a time when 'shape matching' to typological holotypes is de rigueur. Thus, a book that outlines the fractographic and fracture mechanic principles behind chaîne opératoire and technological analysis is important because understanding fractures is essential to interpreting knapping (Tsirk, 2014: ix). The book's relevance is evident in the content of its three parts. Part one briefly considers the tools and techniques of knapping (chapters 1 and 2) and raw material types (chapter 3). Part two introduces the formation and meaning of fracture attributes (chapters 8

Published by the School of History, Classics and Archaeology, University of Edinburgh ISSN: 2055-0472. URL: http://journals.ed.ac.uk/lithicstudies/

This work is licensed under a Creative Commons Attribution 2.5 UK: Scotland License. 
to 9). Part three (chapters 10 to 13) describes how fractography relates to knapping. It concludes with a few brief remarks (chapter 14), a glossary, references and index. However, this structure obfuscates the author's arguments and impacts on the content for four reasons.

Firstly, parts one to three are written as if they were Tsirk's chapters, and the chapters (chapters 1 to 14) are composed as if they were subsections of them. This impacts on the content as the arguments are not always clear because of the paucity of standard academic structure. For example, the tripartite structure distributes the arguments across the book (rather than in single chapters). Also, there is a lack of introductions and conclusions in most chapters, a virtual omission of explicit aims (in each part, chapter, or section), an overall lack of discussion signposting, and the definition of terms in the main text is poor. Secondly, Tsirk does not provide an adequate methodology. Thirdly, despite claiming empirical rather than theoretical understandings and the re-examination of his samples (Tsirk, 2014: 23) he provides relatively little supporting data. Fourthly, Tsirk's data descriptions are intermixed with interpretation. Consequently, these issues obfuscate his arguments and result in a largely theoretical book. This prevents the reader from coming to the same empirical understanding as Tsirk. Clearly, an academic structure, methodology, and more data (with a separation of it from interpretations) would be beneficial.

In part, the conflicting objectives caused the structural issues. For instance, the book is aimed both as an introductory text on fractography, and for fractographers on the types of fractures in knapping (Tsirk, 2014: ix). Internally, part one is aimed at fractographers, part two-knappers, and part three at both constituencies (Tsirk, 2014: 232). However, since an overriding emphasis - demonstrating knapping to fractographers - is more apparent, he meets none of his aims. Additionally, given both the subject complexity and the obfuscated explanations, this book is not at the claimed elementary level for non-archaeologist knappers. Rather, it is more suitable for seasoned researchers who have sufficient knowledge and do not need to decipher the book's structure. Moreover, his restricted notion of knappers solely to people who knap (i.e. not necessarily archeologists) means the book is not aimed at - though is useful for - lithic researchers and lithic analysis. Thus, important technological concepts including chaîne opératoire and reduction trajectories are not considered. This hinders his attempts to demonstrate the usefulness of fractography and fracture mechanics for the elucidation, analysis, and verification of interpretations of past lithic exploitation. Likewise, apart from a brief discussion on raw materials (chapter 3), there is comparatively little on the effects of mechanical properties on fracture mechanics. For example, the omission of any discussion of flaws and inclusions that interfere with Hertzian force waves (and hence the predictability of fractures and the workability of a material) is a significant weakness. Moreover, since raw materials play such an important role in affecting knapability, it should have figured more prominently in the book. As a consequence, Tsirk ultimately fails to deliver the required detail, differing levels of supporting evidence and explanations for each potential constituency.

Notwithstanding the issues noted above, this book remains a significant work. It represents Tsirk's most comprehensive and accessible work and a major contribution to the field. Despite the obfuscations and the general lack of data, the arguments are logical and stand up to scrutiny with careful reading. Its main strength is that it is the first book solely dedicated to understanding knapping, fractography, and fracture mechanics from a single perspective. Therefore, to conclude, despite its issues, the detail of the explanations (albeit somewhat drawn out), the diagrams, and micrographs make this a useful manual for experienced researchers. 